\title{
ENTRE O MEDITERRÂNEO E O ATLÂNTICO, UMA AVENTURA TEATRAL
}

\section{Jogos e práticas teatrais permitem intercâmbio cultural alargando o conhecimento e a tolerância com o "diferente"}

Quando Chama encenou a primeira parte da vida de Asmahan, jogou um tapete verde sobre o piso do terraço para que pudéssemos visualizar as florestas das escarpadas das montanhas de Druze onde a princesa havia nascido. Em seguida, Chama pôs um sofá na frente da cena para representar a cama de Asmahan e besuntou de cosmético khol a área em volta de seus olhos a fim de sugerir os olhos verdes sonhadores da princesa. $O$ cabelo deu mais problema - o da heroína era negríssimo - $e$ Chama viu-se obrigada a cobrir com um turbante cor de carvão os cachos castanhoavermelhados que punham tudo a perderl.

Estamos em um harém doméstico em Fez, no Marrocos sob dominação francesa, anos 40. Chama e outras mulheres do extenso grupo familiar se refugiam no terraço ao ar livre, espaço encantado onde o imaginário pode se materializar através dos corpos em ação. Objetos de cena se aliam a recursos de maquiagem e figurino, para tornar metaforicamente presente a princesa libanesa. Acomodada no chão, parte do grupo forma a platéia, ativamente envolvida na dramatização através de cantos e indicações dirigidas aos que atuam.
$O$ fato de nunca terem assistido a um espetáculo teatral, na acepção estrita do termo, não constitui obstáculo para a representação simbólica dos temas que concernem de perto ao grupo de mulheres reclusas lideradas por Chama. A meio caminho entre o fazde-conta e o teatro, esse agir como se contribui para que elas se situem em relação a si mesmas e ao meio no qual estão inseridas.

A relevância dessa capacidade inerente a todo ser humano, de tornar presente um ser ausente através da representação, está na base de processos de aprendizagem da linguagem teatral, dirigidos àqueles que por ela se interessem, independentemente de qualquer noção de talento ou de projeto de profissionalização. Nessa perspectiva, o fazer teatral deixa de ser encarado de modo restrito ao espetacular, passando a ser equacionado em termos das contribuições que oferece para o desenvolvimento do homem, segundo valores como a abertura para a experiência ou o trabalho coletivo, por exemplo.

\section{A AUTORA}

\section{Maria Lúcia de Souza Barros Pupo}

Professora Associada do Departamento de Artes Cênicas da Escola de Comunicações e Artes da USP. 
Corte no tempo. Estamos agora em Tetuán, antiga capital do protetorado espanhol no Norte do Marrocos, em 1996. Algumas placas parecem curiosamente familiares à pesquisadora brasileira. Nomes como Cabo Negro, Cinema Avenida ou Restaurante Restinga, remanescentes do domínio espanhol, fazem vir à tona os fortes vínculos tecidos entre as duas culturas, ao longo dos sete séculos que durou a presença islâmica na Península Ibérica. À vista de tais nomes, a consciência do grau da influência da cultura árabe na colonização do Brasil é imediatamente reativada. Por outro lado, um passeio pela medina, porção mais antiga da cidade, trama de ruas e passagens estreitas numa organização labiríntica, remete de imediato à estranheza fascinante das Mil e uma noites.

Uma pequena parcela da população de Tetuán, formada por estudantes de três instituições, a École Normale Supérieure, o Institut National des Beaux Arts e o Institut Français, constitui o grupo de pessoas com as quais se inicia uma pesquisa-ação coordenada pela brasileira recém-chegada.

Para esses estudantes, diferentemente do caso de Chama e suas companheiras, o espetáculo teatral, tal como concebido no Ocidente, não é um fato inédito. A ocorrência esporádica na cidade de representações teatrais realizadas por grupos franceses e, mais raramente, por grupos oriundos de outras cidades marroquinas, no entanto, não chega a assegurar o interesse desses jovens adultos pela arte da cena. Por outro lado, múltiplas práticas espetaculares, tais como rituais vinculados ao culto dos santos, danças que levam ao êxtase ou o teatro de ma- rionetes, que até há alguns anos constituíam importante dimensão da vida simbólica dos marroquinos, hoje estão praticamente ausentes de Tetuán. Até mesmo a tradição do contador de histórias em sua halka² se transformou em legado do passado.

A pesquisa-ação que se tinha em vista dentro do Institut National des Beaux Arts (INBA) e do Institut Français (IF) pretendia desenvolver processos de aprendizagem teatral junto àqueles estudantes, no âmbito de uma ação cultural que permitisse a emissão de discursos teatrais originários dos próprios grupos. No caso da École Normale Supérieure (ENS), havia uma perspectiva específica: esperava-se que os docentes em formação pudessem utilizar os conhecimentos a serem adquiridos quando viessem a atuar como professores de francês no curso secundário. A formulação desse trabalho daria continuidade a uma investigação já iniciada em São Paulo. Ela dizia respeito a processos de aprendizagem da linguagem teatral fundamentados em elementos lúdicos, que aliassem ação improvisada e abordagem de textos narrativos.

\section{EXPERIMENTAÇÃO DE PRÁTICAS TEATRAIS}

Nossa intervenção em Tetuán partiu, portanto, do pressuposto ao qual nos referimos acima: a possibilidade - democraticamente partilhada por todos os humanos - de agir como sendo outro, dentro de limites circunscritos de espaço e tempo, ou seja, a possibilidade de atuar dramaticamente. Assim fundamentada, a investigação iria enfa- 
tizar a importância do desenvolvimento dessa capacidade de jogo, enquanto fator que conduz o indivíduo à ampliação da consciência sobre sua inserção no mundo.

O objetivo preciso consistia em proceder à construção, experimentação e avaliação de práticas teatrais que articulassem jogos e textos de caráter narrativo. A médio prazo, pretendia-se que os resultados obtidos abrissem novas e concretas perspectivas para a formação de docentes em teatro pela Universidade de São Paulo.

A idéia de integrar jogo teatral e texto narrativo encontrou no Marrocos um terreno privilegiado. No mundo árabe, em que a palavra vem a ser fundadora da civilização, não é o dramático, mas sim o épico que caracteriza as manifestações mais relevantes da literatura. $\mathrm{O}$ conhecimento da visão de mundo árabe passa necessariamente pelo exame de manifestações como a narrativa, a fábula, o provérbio e o ditado. Nesse sentido, cabe lembrar as palavras de Anatol Rosenfeld: "A maneira pela qual é comunicado o mundo imaginário pressupõe certa atitude em face desse mundo ou, contrariamente, a atitude exprime-se em certa maneira de comunicar. Nos gêneros manifestam-se, sem dúvida, tipos diversos de imaginação e de atitudes em face do mundo"3.

\section{OFICINAS: AÇÃO E IMPROVISO}

Em oficinas nas quais se experimenta o teatro de maneira lúdica, a intervenção do coordenador ocorre de modo a propor gradativamente modalidades baseadas nos elementos fundamentais da linguagem cênica: espaço, ação, personagem. Criam-se assim condições para que o papel do jogador possa emergir no próprio momento do jogo, não sendo ensaiado anteriormente, nem imposto de fora. Nesse processo, a relação interpessoal, que possibilita a cumplicidade dentro da ação improvisada, tem um destaque especial. Uma parcela do próprio grupo, em alternância, atua como platéia envolvida no processo, dando retorno aos jogadores acerca das soluções por eles obtidas.

Estávamos diante de uma pesquisaação que se configurava como uma área de cruzamento entre teatro, literatura e pedagogia. Juntos, coordenadora e participantes deveriam extrair de um processo de experimentação coletiva procedimentos que satisfizessem a esse desejo de fusão entre jogo teatral e texto. Em diferentes níveis, portanto, uma série de encontros se anunciava naquele ponto do planeta em que o Mediterrâneo e o Atlântico se entrelaçam.

Quando se procura caracterizar o universo marroquino hoje, talvez a noção de conflito - teatral em si mesma - seja a que melhor possibilite esboçar um quadro dos impasses daquela cultura. Por um lado, observa-se a força de preceitos religiosos ancestrais. As relações cotidianas entre homens são reguladas pelo Alcorão; a crença e a prática religiosas são internalizadas como evidências; homens e mulheres vivem em universos paralelos. Se os corpos tendem a ser negados, o corpo feminino é sistematicamente velado e os contatos envolvendo ambos os sexos costumam ser cercados de proibições. No entanto, simultaneamente a essas peculiaridades tradicio- 
nais da vida em sociedade, a industrialização progressiva, os novos hábitos de consumo e a eclosão de padrões de comportamento em ruptura com modelos antigos, difundidos pela mídia, revelam o crescente fascínio exercido pelos valores ocidentais. Comprimido entre o apelo à autenticidade e o desejo de poder se beneficiar com as conquistas do Ocidente, o marroquino vai forjando suas respostas - muitas vezes carregadas de resíduos conflituais - através de acertos feitos consigo mesmo.

Assim sendo, antes do início da investigação vieram à tona, de modo contundente, questões incontornáveis sobre a viabilidade de um processo de ação cultural dentro do contexto no qual nos propúnhamos a agir. No decorrer dos encontros, quais dos limites ou benefícios dessa ação cultural poderiam vir a ser atribuídos à especificidade da cultura islâmica? Que incidências teria sobre o processo o fato de uma brasileira, recém-chegada a Tetuán, ser a responsável por sua coordenação? Correríamos o risco, tanto os participantes quanto a própria pesquisadora, de possuir, talvez de modo não consciente, visões apriorísticas sobre os padrões culturais do outro?

Uma vez formados os grupos de jogadores voluntários nas três instituições, iniciaram-se as oficinas, em francês, a segunda língua oficial do país. Propusemos procedimentos baseados nas noções de jogo teatral e de jogo dramático ${ }^{4}$. Nos primeiros encontros, o clima revelava curiosidade por parte dos jogadores, assim como considerável cautela tanto por parte deles, quanto da pesquisadora.
Muitos foram os cuidados presentes na condução das oficinas, visando a não ferir, ainda que involuntariamente, os padrões culturais vigentes, sobretudo nas sessões iniciais: a atenção à própria vestimenta, o teor da linguagem empregada, os movimentos e a gestualidade manifestados em cada encontro.

Todos os sentidos se mantinham ainda mais especialmente apurados do que o habitual em situações similares, na tentativa de decodificar atitudes e reações dos estudantes marroquinos.

Paulatinamente, jogos visando à intensificação da consciência sensorial, assim como outros, tendo em vista a comunicação não-verbal, através de imagens corporais, ritmos, gestos, objetos, começaram a ser experimentados com crescente prazer.

As propostas lançadas pela coordenadora configuravam-se como problemas de atuação a serem resolvidos coletivamente, a partir da temática que o grupo quisesse abordar. Assim, por exemplo, se apresentava o enunciado de uma proposta para resultar em comunicação não-verbal, emitida pela pesquisadora: "Em subgrupos de quatro ou cinco pessoas, estabelecer acordo sobre um objeto a ser transportado coletivamente, concentrando-se em torná-lo real; após, a platéia dirá qual foi o objeto visto". Desse modo, o aprendizado da comunicação teatral acontece através do universo que os jogadores querem fazer vir à tona; sua visão de mundo pouco a pouco vai se revelando, sem que haja sugestões temáticas por parte da coordenação da oficina.

4. Sobre essas noções consultar, respectivamente: SPOLIN, V. Improvisação para o teatro. São Paulo: [s.n.], I978; e RYNGAERT, J. Joeur, représenter (Jogar, representar). Paris: [s.n.], 1985. 


\section{JOGOS E AÇÃO CÊNICA}

Uma vez conhecidos os princípios e as regras que constituíam a moldura do trabalho conjunto, uma relação de confiança foi se estabelecendo dentro dos grupos, o que permitiu que os jogadores conquistassem novas capacidades simbólicas vinculadas à corporalidade. A reflexão - oral e escrita sobre a experiência vivida constituiu uma vertente igualmente importante do processo. Dois trechos de depoimentos escritos revelam o teor do aprendizados:

A proposta de jogo libera o espírito e o corpo vai junto. (M. T., ENS)

Aprendi a aceitar o olhar do outro, a liberar meu corpo e permitir que ele se exprima sem vergonha e sem complexos. $\dot{E}$ maravilhoso experimentar todos os sentimentos humanos sem vivê-los na realidade, é fazer uma prospecção mais profunda no interior de si mesmo. (A. H., INBA)

Na sequiência, jogos abordando a ação cênica, a relação entre o espaço real e o lugar fictício, assim como a construção de personagens através de fragmentos de figurino, de associação com a movimentação de animais, ou de imagens corporais trocadas entre os jogadores, favoreceram a formulação de novos conhecimentos sobre as funções do teatro e sobre as próprias competências dos participantes. O seu testemunho é eloqüente:

Os jogos continuavam e pouco a pouco nos revelavam seus objetivos não declarados de antemão, mas progressivamente descobertos... A aprendizagem se fazia sem o recurso a uma "ciência" exterior ao âmbito do nosso grupo. (M. T. e H. T., ENS)
Ao se lançar nessa aventura coletiva, os jogadores são submetidos a um contínuo esforço de improvisação e ajustamento recíproco. O jogador se aplica, se depara com tudo o que é aleatório dentro do jogo e, ao mesmo tempo, desenvolve sua capacidade de escuta, ou seja, a mobilização de todos os seus sentidos a fim de acolher as propostas do outro, de explorá-las tendo em vista alimentar e retomar o jogo. (A. C. e D. D., ENS)

Aprendemos que em arte não se escamoteia e que a única maneira de convencer um público é ser completamente sincero consigo mesmo. (R. H., ENS)

Um de nossos princípios de atuação era levar o grupo a perceber que apropriarse do texto é estabelecer relações significativas com ele e a partir dele. No âmbito dessa pesquisa, a apropriação de textos se desdobrou em propostas que levaram os participantes a precisar, recortar, ampliar, deslocar, criticar significados desses textos, através de ações de caráter lúdico.

Muitas foram as modalidades lúdicas experimentadas a partir de diferentes tipos de texto narrativo, como contos, novelas, fragmentos de romance. Entre os autores, estiveram presentes tanto os anônimos das Mil e uma noites, quanto escritores marroquinos contemporâneos.

\section{JOGOS TEATRAIS COM PROVÉRBIOS}

Destacamos aqui apenas uma dessas modalidades. Trata-se de um procedimento lúdico formulado para o tratamento de provérbios que, na terminologia de André Jolles, são chamados de "formas simples". 
A vida cotidiana no Marrocos é especialmente permeada por provérbios e ditos populares. Com grande frequiência eles aparecem no discurso de pessoas de todos os níveis sociais, que lhes atribuem invariavelmente um valor de exemplo.

No seu bojo se encontra implícita uma comparação entre a situação nele evocada e a situação presente do indivíduo que dele lança mão, projetando uma tradição sobre o momento atual. Caracterizados por alta dose de condensação, os provérbios são sem dúvida excelentes instrumentos para conhecer mentalidades, gostos e concepções.

Partimos de um universo de provérbios traduzidos do árabe dialetal para o francês, alguns deles deliberadamente escolhidos pelos membros das oficinas ou sorteados. O jogo resultaria da associação entre o enunciado e uma situação dramática inventada pelos jogadores.

Sabíamos, no entanto, que a preocupação exclusiva com a formulação da linearidade do enredo tenderia a empobrecer a densidade das soluções cênicas.

Propusemos modalidades lúdicas que permitissem associar a formulação expressa através do provérbio com o tema que os participantes quisessem abordar, sem perder de vista o tratamento de aspectos específicos da linguagem teatral. Isto significava que cada rodada de jogo traria à tona uma situação dramática vinculada ao provérbio, acrescida de um problema cênico a ser resolvido.

Limitamos o campo das soluções possíveis, mediante a proposta de combinação, através de sorteio, entre personagens - pre- viamente elaborados através de fragmentos de figurinos ou silhuetas esboçadas corporalmente - e lugares sugeridos pelos participantes. Uma vez estabelecidas, essas combinações aleatórias formavam a aliança entre o quem e o onde. Caberia a cada subgrupo de duas a cinco pessoas determinar $o$ $q u \hat{e}$, ou seja, a ação a ser desenvolvida entre aqueles personagens, naquele lugar, tendo em vista fazer emergir a noção contida no enunciado proverbial. O problema teatral a ser focalizado seria o de tornar fisicamente perceptíveis o lugar da ação e os objetos a serem manipulados, construídos com significantes imaginários.

\section{SUCESSO DAS OFICINAS}

Dois exemplos ilustram as trajetórias dentro das oficinas no que diz respeito aos jogos teatrais com provérbios.

1) A palavra de quem tem ouro é exaltada e a palavra do homem pobre, rejeitada.

Numa cela, três presidiários mantêm entre si uma nítida hierarquia. Um deles é um homem rico e autoritário, que exerce seu poder sobre um segundo, obrigando-o a desempenhar papel de palhaço, o que é feito de modo patético e servil. Este último, por sua vez, subjuga um terceiro, derradeiro elo da cadeia de exploração. Em dado momento, o primeiro recebe a notícia de que será libertado, emitida em voz off. Dirige-se a um personagem imaginário, tentando convencê-lo a deixar que o palhaço também saia da cadeia. O contentamento manifesto em seu rosto revela que o pedido foi aceito. Ambos partem, juntos. $O$ terceiro homem, apesar de suplicar por sua liberdade, nada consegue e permanece sozinho na cela. A cena ocorre sem fala, 
com grande concentração dos jogadores, que se comunicam através do olhar e das ações. O espaço restrito e as grades da prisão são tornados reais a partir da movimentação e dos gestos dos três participantes. A maquiagem usada pelo jogador palhaço causa impacto entre os estudantes da platéia, que analisam seu efeito. $O$ clima, absolutamente não realista, é poético e melancólico (ENS).

2) Ele compra o peixe que ainda vive no mar.

Uma jovem caminha com uma amiga em direção a um hammam - balneário público - enquanto lhe relata suas expectativas em torno do encontro amoroso que teria logo a seguir. Explicita a importância do banho para que pudesse se sentir suficientemente segura de si diante do homem desejado. Despede-se da amiga. Chega ao local, despe-se e começa a se banhar, quando, repentinamente, termina a água. Coberta de sabonete e xampu, oscila do ataque de cólera ao completo desânimo. Conclui-se a cena e a platéia destaca os aspectos importantes daquilo a que tinham assistido. $O$ chuveiro tinha sido solucionado de modo interessante, na medida em que era figurado por uma estudante da oficina, de pé, com a cabeça abaixada entre os dois braços estendidos perpendicularmente ao tronco. Os objetos imaginários - sabonete, torneira, xampu - tinham estado palpáveis, contribuindo para a intensidade do jogo (INBA).

A tessitura de relações entre os jogadores e os provérbios ocorreu no âmago da

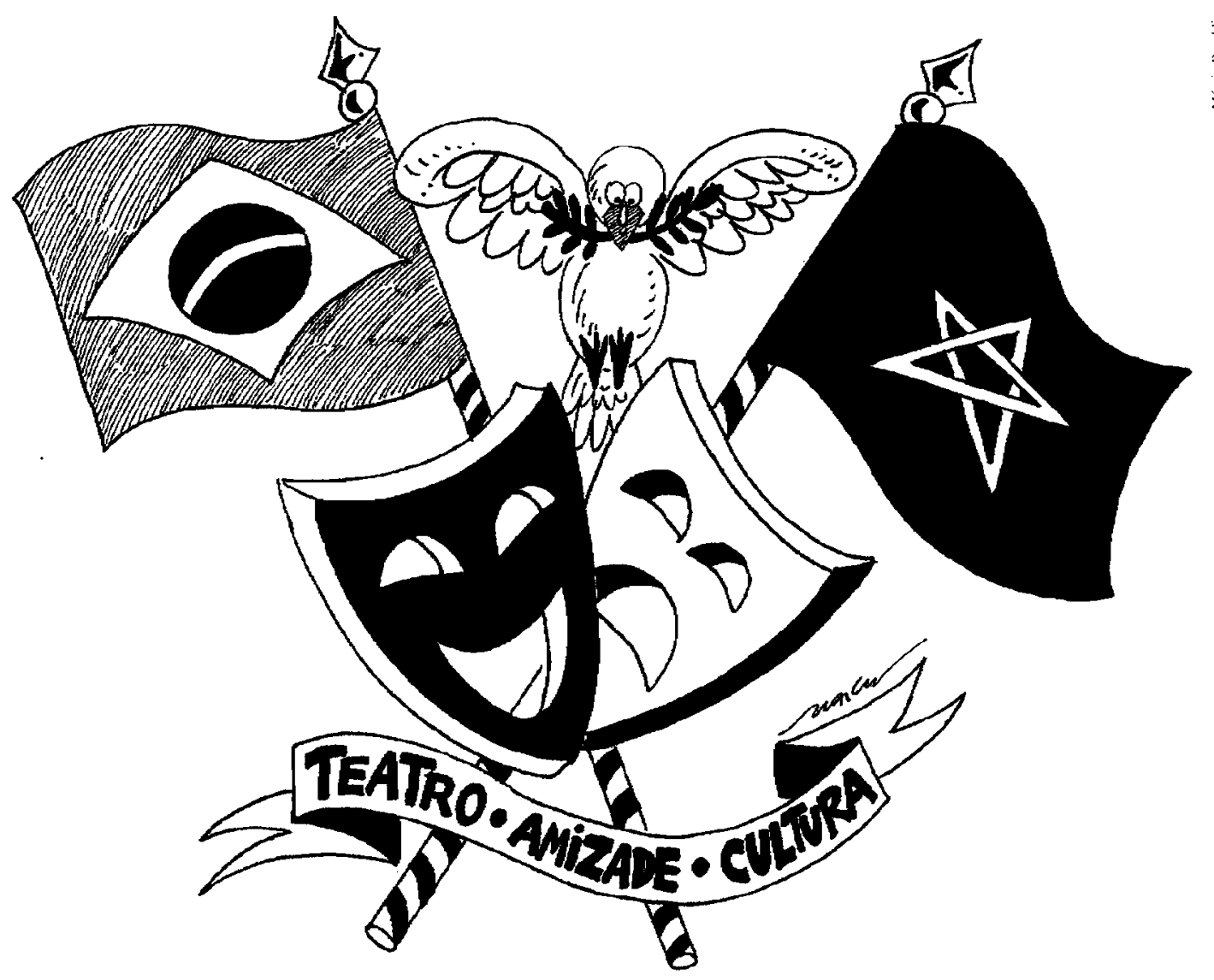


própria descoberta da linguagem cênica. Essa ficção elaborada pelos participantes através de um discurso teatral próprio, propiciado por enunciados proverbiais, corresponde a um recorte apenas, entre muitas outras modalidades de relação entre texto e jogo experimentadas ao longo de um rico processo de oito meses de trabalho.

\section{ÊXITO DA LINGUAGEM TEATRAL}

Durante esse período, sobretudo nas primeiras semanas, a coordenadora tinha como tácita idéia de que era inevitavelmente vista como "exótica" na perspectiva dos diferentes grupos. Reiteradas menções elogiosas à cultura brasileira no que tange ao futebol, carnaval, novelas e música popular, nessa ordem, de certa maneira confirmavam aquela sensação. A sutil estranheza vivenciada por ambos os lados, no entanto, nunca constituiu propriamente uma dificuldade. Pelo contrário, estimulava o desejo de compreeender o outro, fonte de tantas surpresas.

Se no início, a leitura do comportamento dos participantes pela coordenação buscava identificar as diferenças, na vã tentativa de circunscrevê-las e aprisioná-las, pouco a pouco o processo de trabalho teatral foi ganhando corpo, passando a nos envolver a todos e a desafiar-nos para conquistas coletivas. Nossa diversidade de práticas culturais, evidentemente, não poderia se dissolver. O processo, no entanto, fez com que deixasse de ocupar o primeiro plano e passasse a ser vista como um trunfo muito especial, constitutivo do acordo que nos reunia e que a cada dia nos impulsionava para novas descobertas em nossa aventura teatral.

\section{O confronto com o outro permitiu o} alargamento das consciências e dessas trocas saímos todos transformados. Para a coordenadora do trabalho e possivelmente também para os membros das oficinas, tolerância hoje é bem mais do que uma idéia vagamente importante; transformou-se em valor cuja plena significação foi gradativamente desvendada no bojo do seu complexo exercício cotidiano.

A relação entre o fazer e o pensar teatral funcionou como uma moldura compreendendo a área de pesquisa. Se o jogo com textos narrativos permitiu aos participantes a renovação de seu olhar sobre o mundo, o contínuo movimento de ir e vir entre o fazer e o pensar as cenas trouxe para o primeiro plano o fenômeno teatral em si mesmo.

A oficina me permitiu conduzir uma reflexão sobre o teatro do interior do próprio teatro. Nossas condições de trabalho não eram luxuosas: uma sala, um carpete que nos protegia do frio, cadeiras e mesas. No entanto, nós aprendemos a movimentar nossos corpos, a dar sentido a suas possibilidades expressivas e a colorir nossas vozes. Acredito que chegamos assim a um teatro que pensa os meios da sua existência. (M. J., ENS)

Ao encerrarmos a investigação, constatamos, agora de modo especialmente nítido, a relevância de seus pressupostos.

$O$ aprendizado de teatro mediante abordagem lúdica diz respeito a todos os seres humanos, ultrapassando a diversidade de padrões culturais e demolindo qualquer prerrogativa de dom especial como pré-requisito. 
Certamente, muitos são os fatores que permitem explicar por que um processo dessa natureza, envolvendo a apropriação de textos narrativos, partilhado por pessoas vinculadas a sociedades tão distintas, foi particularmente esclarecedor para todos nós. Alguns desses aspectos podem ser aqui ressaltados.

Os grupos envolvidos dispunham de plena autonomia para estabelecer os limites do seu envolvimento no processo. Nunca existiu a tirania de um ponto de chegada a ser necessariamente alcançado, seja na figura de uma montagem final, seja em termos do desbloqueio de padrões e atitudes diante do corpo. Esse cuidado tornou possível o estabelecimento de um clima de confiança que fez crescer a disponibilidade para o jogo cênico.

Receios legítimos dentro do contexto marroquino eram passíveis de virem à tona. $O$ relato oral de um participante revelou, por exemplo, o alívio sentido quando, dentro de uma improvisação, encontrou uma solução teatral que o liberou de um contato físico previsível com a mão de uma colega, contato esse considerado potencialmente excitante no plano sexual.

Resumo: Esta é uma reflexão sobre o trabalho desenvolvido pela autora como coordenadora de uma pesquisa-ação com oficinas de jogos e práticas teatrais, com estudantes universitários marroquinos, na cidade de Tetuán. $O$ trabalho tem por objetivo demonstrar a conveniência da experimentação e avaliação de práticas teatrais que articulam jogos e textos narrativos, e como eles resultam positivamente na formação de alunos e professores. A pesquisa-ação considerou o ambiente cultural do mundo árabe $e$ procurou a articulação das práticas e jogos tea-
Em outro grupo, uma moça reivindicou que determinada passagem de uma gravação em vídeo, na qual seu personagem era visto dançando (ação escolhida por ela mesma), fosse eliminada durante a edição final, tendo em vista a possível incompreensão de seu pai e irmãos, eventuais espectadores; seu pedido foi atendido. $\mathrm{O}$ limiar considerado como aceitável para cada situação era assim estabelecido pelos membros das oficinas. Isso não impedia, contudo, que em certos casos ele chegasse a ser veladamente debatido por alguns dos participantes.

A intervenção da coordenadora, no sentido de que os estudantes se apropriassem dos textos e avançassem no conhecimento da comunicação teatral, operacionalizava-se principalmente como contínua solicitação da percepção sensorial e da capacidade de análise dos participantes. Alimentava assim uma seqüência de descobertas cujo protagonista só poderia ser o próprio grupo.

Através dessa pesquisa, uma ação cultural foi efetivada. Se os membros das oficinas teatrais em Tetuán detêm hoje um novo meio para articular sua visão de mundo, é tão-somente a eles que cabe, agora, assumir posições sobre as metas e as modalidades da utilização desse novo conhecimento.

trais com a tradição cultural dos provérbios, levando os grupos de alunos a apropriarem-se do texto e estabelecerem relaçōes significativas com ele e a partir dele. O resultado mostrou a conveniência da linguagem teatral na formação dos estudantes, mas também demonstrou como a linguagem teatral é importante para o respeito e o intercâmbio cultural.

Palavras-chave: linguagem teatral, jogos teatrais, cultura, provérbio, mundo árabe, Marrocos 
Abstract: This is a reflection on the work carried out by the author as the coordinator of a research-action using game and theatre practice workshops, with Moroccan university students, in the city of Tetuán. The work aims at demonstrating the convenience of experimentation and the evaluation of theatre practices that articulate games and narrative texts, and how they result positively in educating both students and teachers. The research-action considered the Arab World's cultural environment and searched for the ar- ticulation of theatre practices and games with the cultural tradition of the proverbs, leading groups of students to appropriate themselves of the text and to establish significant relations with it and from it. The result showed the convenience of theatre language to educate students, but also it demonstrated how theatre language is important for cultural respect and exchange.

Key words: theatre language, theatre games, culture, proverb, Arab World, Morocco 